\title{
10 Circles and spirals
}

\author{
Ravi Prabhu, Anne M. Larson \\ and Carol J. Pierce Colfer
}

\section{Introduction}

Here we are, nominally at the end, but really only at the beginning. It should be clear by now that we have entered the histories of people and forests somewhere in the middle, their beginnings lost in time, their futures beyond our compass. The ancient Greeks visualized this as ouroboros, the snake that eats its own tail, and understood it as a loop, a cycle, the depiction of the neverending story. This may be the story of the people and their forests, but the story of ACM is a little different.

That story would best be depicted by yet another ancient symbol, the spiral. The Greeks, always to be relied on in such circumstances, have a triple, interconnected spiral called the triskelion, which, in many ways, captures the essence of what we hope ACM will lead to - a spiralling out and up, one of collaborative, structured learning, with improved outcomes for people and their environments.

The ACM process spirals out from co-created and shared evidence, from a shared vision of a better future and from collective actions to achieve it, seeking to make collective sense of what is happening and to enhance it. Within a shared framework of history, preferences and aspirations, ACM participants act within and upon this shared framework in the awareness that outcomes may not match expectations. Better said, ACM embodies the ambition of making an improved collective sense of what is happening within a shared framework of aspirations for better and more sustainable outcomes.

A number of the authors of the preceding chapters have tried to look under the hood of these ambitions, to describe and analyse the practical steps that make up ACM in order to determine whether they actually led to improved outcomes. They analysed roles of proximate actors - primarily those in their communities - and distant ones, the government for example. The focus was on actors who matter or "count," although this is not always immediately knowable. We are led to wonder, does ACM successfully harness the power of the "adaptive learning and action" spiral and lead to improvements? And if so, how does it do that? This is the central question we address in this chapter as we look across the landscape traversed earlier. 
Before that, however, we examine this book's chapters to convey our present understanding of ACM in "Revisiting adaptive collaborative management: What it is," distinguishing it, for example, from the participatory action research used to catalyse and investigate the emergence or consolidation of ACM processes. We carry forward Fisher and Jackson's (Chapter 9) discussion of the distinction and overlaps between ACM's "research," "action" and/or a combination of the two. That ACM is not a technocratic solution is clear from the previous chapters. Rather, it is a body of knowledge, a framework for a principled approach that helps locate and finetune interventions that connect and optimize existing processes of social interaction and exploration into collective endeavours for social enterprise and change. We spend some time here on understanding how differences - power, gender, endowments, training seem to have affected both the pragmatic course of ACM and the outcomes we aspire to ("From cycle to spiral: Does ACM actually help?"). We also take a shot at laying to rest one of our epistemological conundrums - does ACM exist in the world like a rough gem waiting to be polished, or only in its foundational components? Is it, as a rough gem, already on the spiral of adaptive improvement and simply in need of better traction to get further up? Or does it emerge, as a result of being coaxed out of its component processes - processes that already exist in some not well-connected form - to deliver an iterative improvement spiral and escape from ouroboros circularity?

Does our understanding of ACM processes and outcomes still hold true if we leave forested landscapes ("Spiralling out: ACM beyond the forest")? We pursue this question into non-forested contexts only briefly here in order to better understand ACM and its potential. Our journey here departs from ouroboros, leaving it behind almost immediately, to spend most time with what happens on the collective learning and action spiral before stepping back to see whether ACM leads to such spiralling out - the triskelion.

\section{Revisiting adaptive collaborative management: What it is}

We draw on the book chapters to explore most fundamentally what $A C M$ is. However, as such a broad concept, we have found that different individuals see it and various projects use it somewhat differently - partly because we are dealing with "wicked problems" (both complex and ever-changing). Here, we briefly return to ACM's history. In this book (and others), there have been multiple uses of the terms participatory action research and adaptive collaborative management. Initially, in our ACM programme at CIFOR, we were focused on the ACM process as an iterative one of improving management in an equitable manner, and we saw PAR as a means to do that, as a tool. We saw ACM as an umbrella approach, encompassing numerous tools (like criteria and indicators, reflexivity, biophysical experimentation, social networking, gender analysis and more).

PAR, as used by others, has not always focused on forests, or even natural resources. PAR, though central to ACM in its iterative quality, was not 
inherently focused on forest management and human well-being, unlike our version of ACM. ACM's initial forest focus allowed us to integrate this social science approach within a CGIAR centre in a way that was unusual within that network. The approach served as an entrée for the use of methods that addressed human factors (termed "human well-being" in our early days), which we deemed much needed but at that time under-utilized.

Others have seen and used PAR as the more comprehensive umbrella. The PAR process has been used in a wide range of settings, far beyond forestry, as shown in Chapters 2 and 9 particularly. Those who have begun with PAR are likely to consider ACM as a special case, focused on forests and their management. Most of our ACM team members over the years have focused on forests and begun with ACM, thus seeing PAR as a subset of tools or approaches of use in the management thereof.

Another element of the "confusion" about ACM and PAR derives from the fact that both recognize the holistic nature of cultural and biological systems. Both address a wide range of concerns. Within ACM, for instance, diverse topics have at various times and with various individuals taken centre stage, within any particular project situating that topic within the system of which it was a part. Examples include:

- Gender and inclusivity (Colfer 2005; Indriatmoko et al. 2007; Evans et al. 2017)

- $\quad$ Social learning (Wollenberg et al. 2001a; McDougall et al. 2009, 2010; Evans, Larson and Flores 2020)

- Monitoring (the collection by Guijt 2007 or CIFOR 1999)

- Governance (Cronkleton et al. 2010; Colfer and Pfund 2011; Flores et al. 2016)

- Equity (Colfer 2005; Wollenberg, Anderson and Edmunds 2001b; McDougall et al. 2013)

- Modelling (Vanclay, Prabhu and Sinclair 2003; Vanclay, Prabhu and Sinclair 2006)

- The future (Evans et al. 2006; Wollenberg, Edmunds and Buck 2000) and

- Collective action (Komarudin et al. 2012)

This diversity also characterizes PAR. The iterative, cycling triskelion process is also central to both.

Another differentiation that has bedevilled our attempts at conceptual specificity and clarity with regard to concepts - more related to ACM than PAR - is that between management and governance. ACM, of course, includes management in its very name; and forest management has been a central pillar of our concerns. However, our initial recognition that ACM processes would have to span levels, from the local "up" to higher levels or "out" to broader scales, quickly brought us into questions of governance - an involvement that has only strengthened. McDougall and Ojha and others have written of "adaptive collaborative governance" (McDougall et al. 2013); see also Chapter 8). 
Colfer once opined that "One could say that management is to a defined organization or sector, such as forestry, what governance is to society at large" (Colfer et al. 2011, p. 26). In early 2021, she carefully read the book Forest Governance and Management Across Time (Marald et al. 2017), seeking a clear differentiation between the two; she found none. One could construct a Venn diagram showing the overlap, with ACM in the intersecting arcs - the overlap perhaps contracting or expanding depending on the varying topics addressed and analyses conducted.

Fisher and Jackson (Chapter 9) focus on whether the action research components of PAR and ACM constitute a legitimate approach to research. They counter a common scientific bias that research needs to be replicable, and perhaps also more quantitative, to be reliable and legitimate. They also discuss their experience of NGO disapproval of PAR as too focused on "research" - a very different complaint from those of scientists but showing the sometimes difficult battle for legitimacy for such participatory methods. In Fisher and Jackson's formulation, ACM does not always have research objectives, but when it does, it has revealed important scientific findings in multiple contexts, as well as leading to important social and practical outcomes. Its distinctive feature is that it permits much better engagement with the specificities of context, which can make or break any project intervention. It permits project organizers to admit that they do not (and perhaps cannot) have the full a priori knowledge required for a successful intervention.

Considering ACM, Johnson and Pokorny (Chapter 2) recognize:

the need to carefully take into account the capacities and agendas of all involved actors, the researchers, technicians, their supervisors, and local research partners. ... It is also clear that collaboration requires more than the simple application of participatory techniques and methods. It requires a true interest in and understanding of the perceptions and susceptibilities of the community and the inequalities related to logistics, lifestyles, expectations and priorities. Adequate training and intensive supervision are mandatory but may sometimes be insufficient.

Further, Cronkleton, Evans and Larson (Chapter 6) also point to the importance of scaling "learning to the needs, interests and capacities of the participants." They go on to point out that these processes can be uncomfortable, particularly when such experiences challenge the assumptions and identities of those involved. Nevertheless, in order to work in and engage with the complex environments of forest communities, everyone has to "learn how to learn" more effectively. Their chapter lays out in detail how this was accomplished.

Learning is integrally related to participation in decision making regarding natural resource management. Mukasa et al. (in Chapter 5) identify the ACM approach as an intervention "designed to enhance participation by all stakeholders (especially marginalized groups) in deliberate community efforts including decision making and benefit sharing." As Bomuhangi et al. (Chapter 4) point 
out, this process can be formalized: ACM can be an approach "where decision making by forest adjacent communities in making rules related to enforcement and benefit sharing has been formally acknowledged by the state," as it seeks to improve management with improved outcomes. Or it can remain informal. In the early ACM sites, several teams opted for the former (e.g., Nepal, Zimbabwe, Malawi), others for the latter (e.g., Brazil, Indonesia). Sites like Bolivia, Cameroon and the Philippines opted for intermediate structures, tying in closely with government policies and institutions, but forming loose local groups.

As Cronkleton, Evans and Larson (Chapter 6) put it, ACM requires that everyone adopt the "learning way," that is, despite the fact that a part of what makes us humans is our ability to communicate, collaborate, learn and adapt, this is a process that benefits from active support, engagement and capability strengthening. Collaborating, learning and adapting through collective action - in a way that is equitable, and with outcomes that are both sustainable and beneficial - is clearly not a trivial task. Seen this way, ACM is a capability strengthening approach as much as it is a management approach.

McDougall and Ojha (Chapter 8) highlight another pervasive dimension to this collaborative learning environment: unequal power relations. One of the reasons that communication and collaboration do not "naturally" emerge is because people are not bringing the same resources to negotiations. As these authors suggest, through their deep theoretical inquiry, assuming a level playing field is unlikely to bring about a successful learning process that promotes the kind of critical inquiry and reflection required to challenge inequalities. Thus, we return to the importance, as emphasized in so many of the chapters, of capacity building at all levels, from the researchers to community participants: it takes considerable understanding, skill and tact to surface implicit assumptions and enable their questioning in "safe spaces."

In Chapter 9, Fisher and Jackson take us through a repertoire of ways that action research has been used - sometimes emphasizing action, sometimes research. Where we (the editors) have focused rather clearly on the use of participatory action research, they write more about "action research," which does not necessarily have to be collaborative, in their view. They discuss action research that has been conducted in several sectors and at varying scales emphasizing its versatility and broad utility.

In our experience, borne out also by the chapters of this book, ACM has to emerge out of strengthening and connecting capabilities that exist in every social grouping - local communities, multi-stakeholder forums, forms of governance. To the extent that it already exists (our unpolished gem), it may mainly need coaxing in contexts where there is already a spirit of collaboration. But unequal power relations can not only keep it from emerging but take it in untoward directions. It thus requires strengthening processes of reflection, based on gathering and analysing evidence that can challenge confirmation biases and entrenched views - including those that underlie unequal power relations. It requires an ability to share and communicate collective insights in 
ways that are equitable and constructive. It involves learning as well as being open to unlearning. Only when the resulting social learning is transformative can we say that $\mathrm{ACM}^{1}$ has emerged. Whether this results in better outcomes or not is the question we turn to next.

\section{From cycle to spiral: Does ACM actually help?}

We turn now to understanding what ACM has achieved. Has it actually helped or not, and if so, how? What made this possible?

In Chapter 9, Fisher and Jackson report a number of action research findings that were essential for understanding local contexts, and which at times led to important changes in policies and approaches. For example, in Nepal, the revelation of indigenous forest management systems and organizations informed the shift from the panchayat (subnational government) model of community forests to the current community forest user group (CFUG) model, one of the most successful community forestry experiences in the world (Gnych et al. 2020).

In Chapter 5, Mukasa et al. document the clearest evidence of the kinds of local management outcomes that ACM processes have helped to deliver: "with the coming of ACM, [previous adverse conditions] have been reversed. The forest has been restored and there are alternative income-generating projects that are not forest based," says one interviewee in possibly the strongest statement of a positive outcome from ACM processes recorded here. But despite seeing changes to "sticky" social norms after six years of ACM, the evidence remains at best mixed (Table 5.7). Changing attitudes, behaviours and norms is clearly what ACM sets out to do on a path to delivering positive outcomes that can be sustained. But we have long known that this is not a quick process in forested contexts, as results from other chapters indicate as well. Indeed, such change rarely happens quickly in any context. ${ }^{2}$

Bomuhangi et al. (Chapter 4) record that "More women in ACM sites reported enhanced participation and quality of participation in forestry management activities as compared with women in non-ACM sites." Mukasa et al. (Chapter 5), using in-depth evidence from their ACM cases, also record evidence for women's empowerment and greater equity in decision making. They note that one woman member of a group participating in ACM was "chosen as a chief in the Buganda Kingdom, a cultural institution, after demonstrating her leadership skills." But they, like other ACM researchers, also note that this requires focused building of capabilities if gender transformative outcomes are to ensue, consistent with what Cronkleton, Evans and Larson (Chapter 6) also show. It must be added that these ACM efforts did focus on women's empowerment, rather than, say, economic empowerment as a whole. They provide evidence for legally recognized ACM groups accessing new opportunities, with improved farming practices and income generation as the result. Self-empowerment through ACM intertwined with legal recognition, mutually reinforcing the groups' forward movement. The mixed results 


\section{Ravi Prabhu et al.}

in Table 5.7 suggest that positive outcomes from ACM processes were more likely if they were able to successfully engage at multiple levels of governance, authority and power, rather than being only locally focused.

Cronkleton, Evans and Larson (Chapter 6) saw in ACM "a way to generate a culture of transparent information sharing and learning in an environment where examples of good governance were rare, and where logging historically had been conducted through bribery, conflict, and clientelism." They too note positive impacts on women's participation and greater acceptance of their views in discussions and reflections. Mukasa et al. (Chapter 5) warn of challenges to the implementation of ACM from power imbalances and elite capture on the one hand or elite resistance on the other when power begins to shift and dependencies may arise, especially from disadvantaged groups - issues that arose (and were dealt with) routinely in ACM sites. McDougal and Ojha (Chapter 8) show how the approach to ACM in Nepal successfully overcame such underlying power imbalances, improving the participation of previously excluded Dalits (marginalized groups) and women in decision making, and the central role that social learning plays in mediating responses and outcomes. ${ }^{3}$

It seems clear that ACM has led to consequential, if mixed, outcomes in all these cases (as well as most others about which researchers have published). In our experience here and elsewhere, we have been able to see examples of improved trust among stakeholders, better negotiation and self-analytical skills, conflict management, bonding social capital and greater self-confidence, in addition to important research contributions to understanding local contexts. Nevertheless, the evidence for outcomes is patchy and responses are variable - though how could they not be, given the diversity of contexts, of locally determined goals, of facilitation skills, as well as the inherent ACM responsiveness to evolving local conditions? All "successes" are notoriously difficult to "prove." This persistent difficulty of measuring success across sites remains a dilemma for donors and management and governance institutions considering an ACM approach.

Fundamental to ACM successes has been their consistent attention to the context where change is being encouraged. All of these (and any genuine ACM) are firmly grounded in knowledge of and interaction with the cultural and ecological realities encountered. Success also appears contingent on how well the ACM approach addresses the distribution of power and authority at any particular level (mostly the local, in these case studies) and across scales within which that level was nested. The clearest indication of successful outcomes reported here were shifts in gender roles. Where these were directly linked to resource utilization outcomes, there were also positive economic outcomes.

Nevertheless, we remain dissatisfied with our abilities to assess the effectiveness of the approach. Our personal experience tells us that enormous changes - of uncertain duration -- have occurred in individuals and communities. We believe that many of the shortcomings of more conventional approaches to "development" are addressed and overcome within ACM - particularly as it 
functions on a small scale. Our efforts at higher levels began later; and we have struggled more at these levels, where we confront power more equivalent to our own (informal power); where trained and committed individuals can be relocated by their bureaucratic superiors and thus lost to the endeavour; where desirable local funding can be withdrawn; and so on. ${ }^{4}$

We also recognize that expecting truly substantive success, long-lasting beneficial change, has been illusive no matter what approach has been used. Our sense is that holistic and multi-scale efforts, like ACM or PAR, are needed, approaches that recognize the systemic and dynamic nature of societies and environments. These qualities and their inevitable variation from place to place and time to time suggest that logically we cannot use conventional experimental scientific methods alone ${ }^{5}$ (seeking generalizability and replicability) as the overarching umbrella approach. These fly in the face of the variability on the ground.

Still, as noted previously, our ability to measure and prove the impacts of our efforts, especially at larger scales, have been limited. In fact, any approach that is embedded in reality is challenging to implement in large, complex socio-political landscapes. The decisions made at local scales, especially in forests, which are rarely locally owned, are deeply influenced by multiple actors (e.g., government, investors) and drivers (e.g., regulations, markets) that originate far from local forests and farms. The effects of ACM, as noted, have so far been mostly local - at least those are the effects we have found easier to document. Shifting the underlying power structures at larger scales, with an ever larger and increasingly diverse - and likely more powerful - set of actors becomes increasingly difficult. The cases presented here and in other research (e.g., Sarmiento Barletti et al. 2020) suggest that efforts in larger political landscapes need to be not only bottom-up but also top-down, with a clear analysis of power and interests and an engaged and theoretically grounded strategy for change (see also Chapter 8).

Although we recognize the need for better measurement of impacts at various levels, one constraint has been that the changes we seek take time; return visits are costly and rare. As we put together this book, we learned of some multi-level successes beyond those highlighted in Nepal in Chapters 8 and 9:

1. In Indonesia, the levels of trust, established among diverse stakeholders in Jambi's ACM programme around 2000, have continued for years after the program ended (Liswanti, Tamara and Arwida 2021, in draft).

2. The Jambi community-based effort to secure rights to manage a protected area was secured, after a decade of effort by the community, an NGO and various bureaucratic levels up to national (thereby contributing to the national experience of effective local management; Yuliani et al. 2021, in draft).

3. In Zimbabwe, where national crises have been recurrent since ACM days (2000-2006), the human resources trained within the Ministry of Forestry have disappeared, though it seems likely that the ACM capabilities they 
acquired may be usefully applied elsewhere. Kozanayi et al. (2021, in draft) document the continued activity of some of the community ACM groups who continue managing as they did during the funded ACM years. ${ }^{6}$

More anecdotal evidence of impacts includes, for example,

1. The meshing of the ACM results in Cameroon with the Canadian Model Forest Program for Central Africa, under the guidance of Chimere Diaw, an early ACM proponent.

2. The network of early ACM researchers in Nepal has continued to work on related forest management issues.

3. Ravi Prabhu's continued use of the approach, as he's shepherded the projects discussed below in Africa.

Sadly, we do not know what may have occurred in several of the original ACM sites (e.g., Malawi, Brazil, the Philippines). ${ }^{7}$

In summary, ACM, in the cases we have discussed here, clearly has helped to improve equity, especially gender equity, especially locally. In some cases, this led to changes in the way forest resources and forests were managed, as men's interests in and needs for these resources were confronted constructively with women's. There remains little doubt that those researchers/facilitators involved gained valuable experience, which no doubt many have continued to use to facilitate similar processes subsequently (e.g., Cronkleton et al., Chapter 6; Yuliani et al. 2015, in West Kalimantan; Colfer et al. 2015a, b, in Sulawesi; and many more). But as with any complex adaptive system, progress evolves in unpredictable directions, is seldom linear and can take varying amounts of time. All this is likely to require changes in beliefs, behaviour and institutions, and rarely happens quickly. And it wreaks havoc with attempts to assess progress.

Ultimately, in forest communities, the capability to adapt collectively to changing circumstances will be of paramount importance to forest stakeholders and their resources. The evidence that ACM improves such adaptive capacity, and therefore lives up to its name, is clearer. It will take longer-term, more consistent and possibly more ambitious engagement to understand whether cultures, conditions and ecosystems at broader scales are also changing for the better.

\section{Spiralling out: ACM beyond the forest}

Looking beyond the forests, and the work presented in the previous nine chapters, we, the three authors of this chapter, take a peek at what is happening with ACM outside the canopy of the trees. We turn to agriculture and the management of common property resources in two short excursions to get a sense of ACM from "outside" its birthplace in the forest. The first of these deals with SHARED, an approach that has been successfully used to support 
subnational decision making in Turkana County, Kenya. We turn then to the wildly ambitious Regreening Africa project that seeks to improve the lives of 500,000 households across eight countries by "regreening" a million hectares of degraded agriculture, essentially by supporting local communities to naturally regenerate or plant trees in their crop and pastoral lands. In these cases, we wanted to open a small window of insight into how multiple, often nested, scales of intervention can be connected through social learning processes with some roots in ACM, nurtured in part from the rich intellectual soils of the forest.

\section{SHARED}

SHARED represents an attempt to move beyond the village or forest management unit level, in addressing agricultural improvements over a broader scale, in an iterative process that retains ACM's responsiveness to local conditions. SHARED incorporates the social learning deemed so important in ACM; and emphasizes previously more latent aspects of communication and decision making. The need to alter attitudes, as discussed particularly in Chapters 6 and 7 , was evident at this intermediate scale (a county), as the county sought to enhance its resilience. The successes to date are impressive.

About one year after Prabhu began engaging with the challenges of agroforestry - integrating trees more effectively into agriculture with crops and livestock - it became apparent to him that there were significant disconnects in the information that flowed between those involved in making decisions about investments in agriculture and the farmers who actually managed the land. The frames of reference and the data and evidence these farmers and broader decision makers used differed. Power, authority and hierarchy further confounded communication, learning and decision making. This was not a particularly new or original insight; but for someone with a history of working in forests and with ACM, it suggested an opportunity. Better connections among the various people and groups operating at different scales could bridge the disconnects, allow new evidence to be considered and improve the nature of decisions based on the social learning that ensued.

In Constance Neely, he found a collaborator with an intuitive understanding for creating connections where gaps existed and a much deeper understanding of agriculture than his own, especially the agriculture of pastoralists: very different because in the management of rangelands and the pasture they provide, water and soil are so dependent on herd size and the movement of these herds through these landscapes. Neely had been charged with helping the county government of Turkana (see Figure 10.1) to improve their development plans as part of a USAID and UN funded effort. She, Sabrina Chesterman and Minu Limbu from UNICEF began looking together at the challenges of opening up entrenched positions and views, including among the technocrats charged with helping to improve the situation. New ways of seeing the evidence would be needed. This was when Tor Vagen joined the efforts with his superlative 


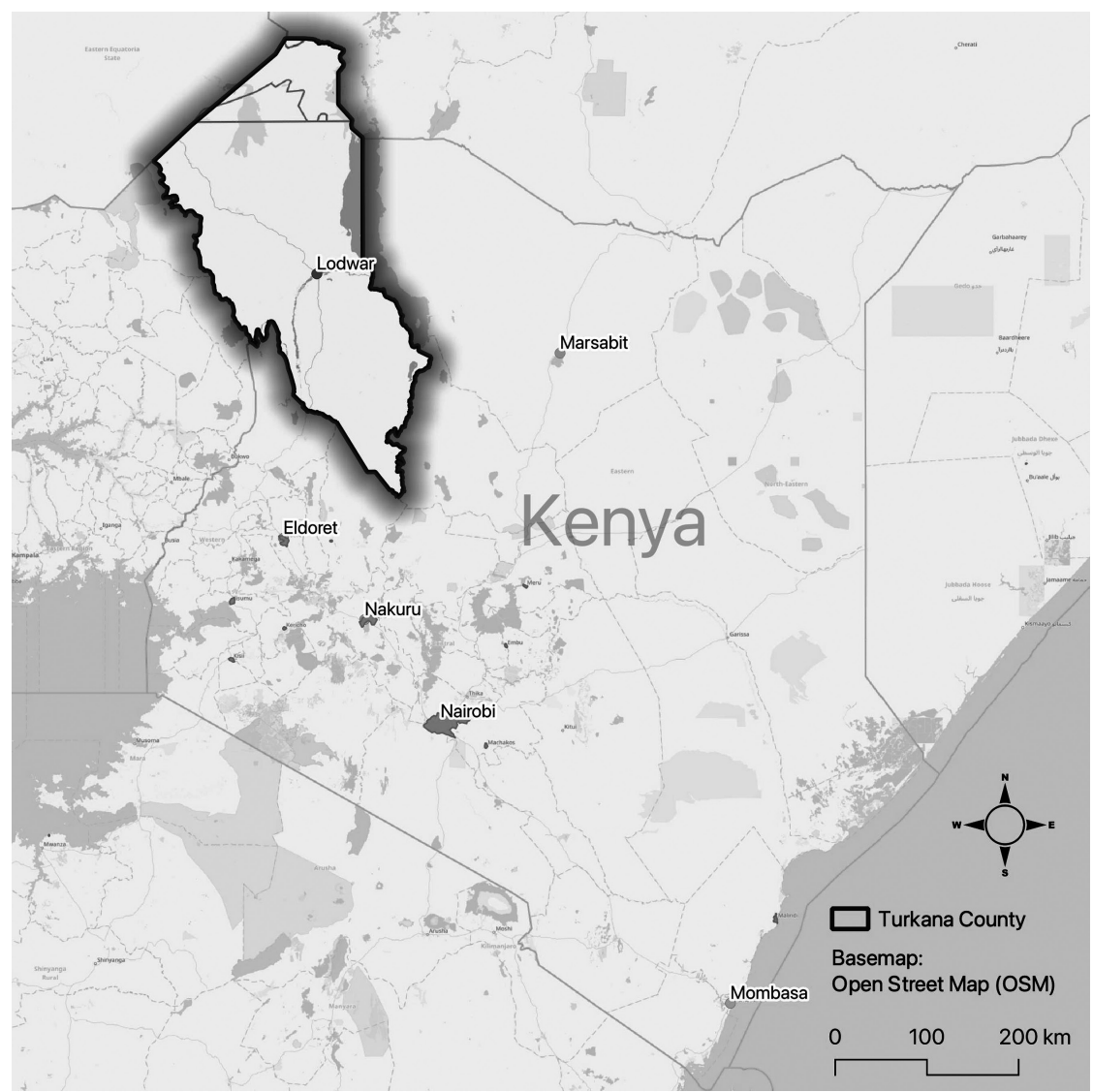

Figure 10.1 Map of Kenya, showing Turkana County.

spatial modelling skills and his deep personal history in the arid counties of Kenya. The result of the evolving ACM was the Stakeholder Approach to Risk-Informed and Evidence-Based Decision Making (SHARED). What follows is drawn from the description by Neely et al. (2021), who reach the conclusion that ACM and multiple loop learning are essential for the kind of institutional learning that leads to better understanding and values, which in turn are essential for organizational change. Essentially, SHARED is a process that enables the co-construction of bridges between different kinds of data and evidence and among different kinds of people, at different levels of hierarchy or disciplinary background. The intent is to facilitate joint understanding, gain insight and make decisions about the group's shared environment.

Key phases in the SHARED framework (see Figure 10.2) ${ }^{8}$ consist of: Context, Integrating Evidence, Prioritizing, Planning and Learning and Responding. The phases are designed to support institutional learning and 


\section{SHARED framework}

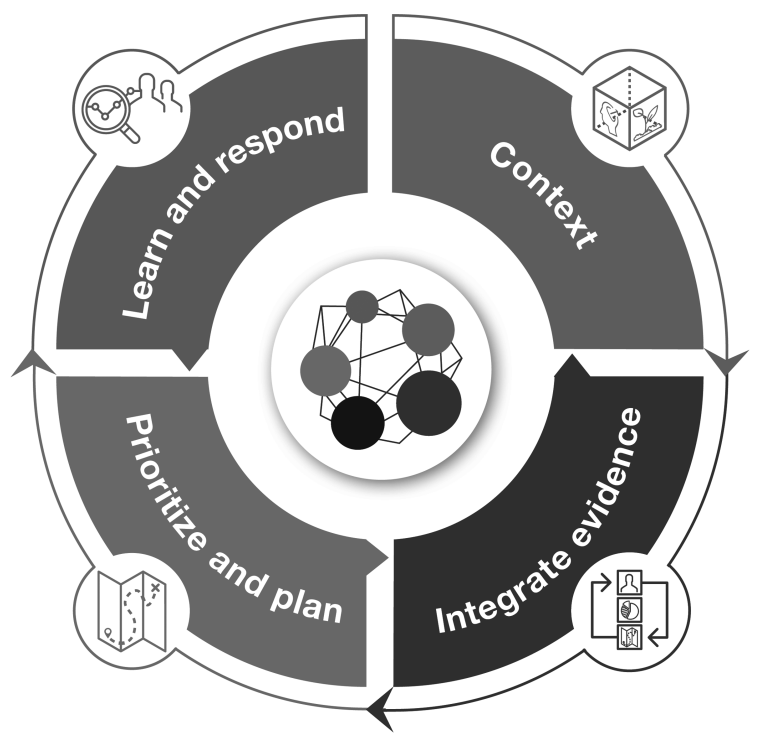

Figure 10.2 The phases of the SHARED Framework.

understanding, shift institutional values and promote organizational change. Neely et al. describe SHARED at length and its impact on decision making in Turkana County. It has since been used in other counties in Kenya and in about ten other countries around the world, with outcomes that varied from changing development plans to the identification of policy gaps. It almost always resulted in better insights into the complex agricultural systems that people were seeking to influence in order to improve their livelihoods (see e.g., Hughes et al. 2020; Vågen et al. 2018; Winowiecki et al. 2021).

Turkana County opted to use the SHARED approach, ${ }^{9}$ with SHARED scientists, collaborators and partners facilitating events with and for a variety of stakeholders. These included local and international civil society, development partner agencies, intergovernmental organizations, sectoral executives and technical staff, county assembly members, national government representatives and scientific and academic partners. Community consultations took place in each of the $30 \mathrm{Sub}-$ County Wards to incorporate local priorities fully in county-level plans.

Based in ACM, the way the SHARED approach was applied in Turkana County in Kenya intentionally integrated multiple loop learning. The results corresponded to institutional learning that contributes to a shift in understanding and values (a form of double-loop learning) and organizational change in the form of changes in norms and policies (corresponding to triple-loop 
learning). The initial policy goal was to enhance the resilience of the Turkana County Government. The actors sought to "make decisions that will have an impact on outcomes - despite the risks Turkana faces." By imbedding institutional learning, they hoped to shift the decision-making culture, as a prerequisite to changing how decisions would be made in the future and formally imbed such decision making in the development of a five-year integrated development plan.

With an aim to shift understanding and values, something that Turkana County officials saw as important for the county's future, the SHARED approach evolved, as represented in Box 10.1. Although functioning on a broader level than many ACM programmes, one can recognize the progression of steps, for the most part, similar.

\section{BOX 10.1 ELEMENTS OF THE SHARED APPROACH}

SHARED evolved towards

a) supporting an understanding of how decisions are taken, based on behavioural and structural influences and self-awareness of the existing decision-making process used by the Turkana County government;

b) co-developing a compelling and commonly held vision, framed in resilience, among a broad set of government sectors, partners and stakeholders;

c) introducing systems thinking and causal analyses for addressing development challenges;

d) creating an evidence culture to motivate securing, managing and using socio-ecological evidence; and

e) facilitating an appreciation for the insights of diverse actors and the advantage of functioning partnerships and collaboration from the community to county level with responsibility for adaptively managing resources.

Though building on ACM, this was a process that emerged out of several workshops that Neely, Chesterman and Limbu facilitated, with active and constructive engagement of Turkana County government officials. Vagen's creativity also proved influential, as he helped to visualize complex data and evidence in ways meaningful to the participants. It was an iterative process of improvement, with SHARED emerging as co-constructed by those involved. Prabhu moved to the back seat and took on the role of a sounding board for the team's thinking - a team that had expanded to include all the authors of the Neely et al. paper (2021). 
Integrating accessible and actionable high-quality evidence into decision making was seen as critical by the participants in the process from the Turkana County Government. They radically changed the way they developed their "County Integrated Development Plan," a plan required of all counties by the central government in Nairobi. They emerged with a sense that they had truly managed to integrate thinking and decision making across various government departments and with local stakeholders. They had overcome skills barriers, adapted the culture of gathering, organizing and storing data, and improved their ability to interpret it, particularly socio-ecological data. They overcame problems of defensiveness associated with displaying data that might reflect negatively on a sector's performance. Their appreciation for the importance of grounded and credible evidence led to the creation of a county data management strategy, a co-designed central web-based and transparent platform for sharing data, the requirement of evidence to support resource allocation proposals, the integration of statistics into the planning department and a monitoring and evaluation framework, department and policy. Ultimately, these changes involved opening them up to information coming from sources other than the bureaucratic channels they had used hitherto. In McDougall's terms, this was a transition to adaptive collaborative governance (2013; or Chapter 8).

Purposeful, structured and continuous stakeholder engagement resulted in more meaningful community participation and deepened cross-sectoral and multi-stakeholder linkages and relationships. This in conjunction with working hand in hand with the pivotal Department of Finance and Economic Planning led to the promotion of coordination and finance mechanisms that foster synergies, cross-sectoral and multi-stakeholder partnerships and transformative pathways.

\section{Regreening Africa}

Regreening Africa, a more recent effort, which began in 2017, takes ACMstyle efforts to an even grander scale (https://regreeningafrica.org/). Again, the project strives for communication, co-creation of knowledge and social learning as central features; and it has negotiated unusually flexible funding (so valuable in a responsive ACM process). The emphasis on restoration - one of the world's foci at the moment - makes this a particularly timely contribution.

About the time the SHARED team in Turkana was winding up its first phase with encouraging outcomes, the European Commission was discussing a major restoration project with ICRAF (World Agroforestry Center). The idea was to use mainly farmer-managed natural regeneration to "regreen" about a million hectares of farm and pastoral land across eight African countries. Involving development-oriented non-governmental organizations like World Vision International, Catholic Relief Services, CARE International and Oxfam, the project would be led by ICRAF- a research organization - intended to benefit 500,000 households. Apart from farmer-managed natural regeneration, the 
Regreening Africa project as it has come to be called, involves tree planting and other forms of agroforestry, complementary sustainable land management interventions along with community mobilization, the formation of multistakeholder advisory groups in addition to teams focused on research and the delivery of knowledge and technical support.

The project was initially conceived as a standard development project where ICRAF, as the "knowledge partner," would provide technical inputs and NGO partners would deliver and implement these with local communities through their teams in the eight countries. However, based on past experience with other projects, success with ACM approaches and the coming of age of SHARED, Prabhu was able to convince a very open-minded, farsighted and engaged team at the European Commission (Bernard Crabbe and Alexandru Ghiurca) to consider modifying the design. His proposed changes were intended to make the project more flexible, integrated and based around adaptive management principles, where it could "learn to improve" as it moved forwards, a rather radical departure from business as usual.

The European Commission team enshrined these ideas in the grant agreement signed with ICRAF; it was then possible for Prabhu to structure this project using principles of collaborative learning. Establishing trust and a basis for collaboration among the research and delivery partners was essential, but a challenge as the integration of research into development in this way was seen as novel there and participants had no real experience of working together. Susan Chomba joined the team as its project manager several months later and instituted a culture of trust, high standards and negotiated agreements that allowed congenial and productive working relationships to emerge and collaborative processes to take root. Institutionally, these were based in the committees, teams, workshops, sharing events and continuous outreach that Chomba and her team led, modelling behaviours that engendered trust.

Just as essential as the collaborative engagement among the project participants was the means to learn effectively together. This meant stepping back from a standard technology transfer model to one where knowledge was cocreated based on the analysis of credible evidence. This meant structuring the project so that evidence and related learning loops would be "hard wired" into it. This was done in two ways - dedicated teams would deliver evidence, some of it co-created, into soft-institutional platforms (informal structures, where rules of engagement are agreed though not formally) where participants could analyse and learn from it. A monitoring, evaluation and learning team (MEL) was designed into the project, and it developed an approach to measuring change based on modifications to standard, mostly extractive techniques of establishing baselines and endlines.

ICRAF has some of the best remote sensing tools for assessing change over time to soil and biomass, and a land degradation dynamics (LDD) team (Leigh Winowiecki and Tor Vagen) was charged with providing this layer of information. The SHARED team, led by Mieke Bourne and Neely, would deliver information from interactive meetings that considered what people understood 
to be happening in the project landscapes; the MEL and LDD teams also provided relevant information. The transfer of the technology team (design techniques implementation - DTI) responded to all three and to information they received from their own meetings with communities and partners, surveys and other assessments. Two further soft institutional platforms were designed into the project at the outset: First, a steering committee that involved the European Commission and all the project implementing partners. This assessed progress against the targets and helped to make adaptive changes to structures, shift funding or even deploy additional funding. This last change became an option as the European Commission and the European Parliament gained faith in the project and what it was achieving. Second, in each of the eight countries, a national stakeholder committee (NOCC) was constituted to guide implementation and adaptation in that country. ${ }^{10}$

Three and a half years into the implementation of this project, learning and adaptation are firmly established in its DNA. So much so that the team has continued to innovate and develop additional collaborative learning mechanisms and opportunities. At the end of the first year, they developed and successfully carried out "joint reflection and learning missions" (JRLMs, see Neely and Bourne 2021); and when the COVID-19 pandemic hit in 2020, they successfully took these missions into cyberspace. Approaches such as "planned comparisons" that promoted experiential learning with the farming communities were introduced, so that new technologies or tree species could be adopted (or not) and adapted to farmers' needs. Throughout the process, an "options by context" approach has been applied to ensure proposed changes and solutions suit the intended beneficiaries and were fit for the social and ecological contexts within which they were being applied. The communications team worked to ensure that information generated in one location could be shared across all. This involved using multiple channels including social media and especially WhatsApp groups, which have proved enormously popular among project participants.

A more recent innovation is a new mobile application (created by Vagen, Ahmad and Winowiecki) that helps lead farmers, government extension agents and project officers to collect data on key indicators of land restoration such as the number and type of species of trees planted; those that survived over different time periods; the GPS location of tree nurseries and the type of tree species they stock; the polygons and management practices in farmer-managed natural regeneration (FMNR) sites; the trainings offered to farmer groups, including women and youth beneficiaries; among other variables. It has become an additional way of monitoring their progress, with data they have generated and which is accessible to them on their own smartphones through a user-friendly online data-reporting system.

While the project has paid great attention to collaboration, learning and adaptation among project investors and implementors, it is less clear how all of this has impacted the communities concerned. ${ }^{11}$ It will not be enough to simply assume that because of discernible changes on the ground in terms 
of tree cover, adoption of new techniques or new tree or shrub species that communities have internalized the kinds of social learning approaches we have identified as ACM or have gained the benefits that have accrued at lower scales. At the same time, a project that had the aim of regreening Africa at 20 euros per hectare would have no hope of meeting its targets if there were no collaborations from the communities concerned and if they were unable or unwilling to adapt. Indeed, current assessments of adoption, innovation and adaptation are very encouraging. While it is still unclear that the ambitious targets will be met, benefits to communities from their endeavours and changes in attitudes and behaviours of development partners are being recorded.

Olaf Westermann of Catholic Relief Services has noted that the nature of the project's structure forced a paradigm shift. "The idea of different international NGOs, who otherwise would be competitors, working together to deliver a common goal is, in itself, a great paradigm shift," he said.

\section{Beyond the horizon: Last thoughts}

There's little doubt that over the last 20 years, there's been a significant global paradigm shift about development, conservation and natural resource management (see Box 10.2).

\section{BOX 10.2 A GLOBAL PARADIGM SHIFT}

Many have recognized that we need:

- new approaches based on systems thinking;

- involvement of a variety of stakeholders in management and governance;

- better interaction between the local scale - such a central focus in the earliest ACM work $^{12}$ - and broader scales;

- recognition that farmers and other rural dwellers have key contextual information, experience and knowledge warranting respect;

- acknowledgement that marginalized groups exist within communities and vis-à-vis other national and international actors, and that the views of such people deserve attention; and

- $\quad$ understanding how power differentials can have devastating results as policies are developed and implemented (or not).

Still, more traditional approaches tend to prevail, particularly in global responses to climate change and biodiversity loss, which are still based largely on topdown visions (e.g., REDD+, zero deforestation commitments, nature-based 
solutions, forest landscape restoration). Local peoples are still an afterthought, or a group to be "safeguarded," or perhaps convinced to change their practices, rather than being seen as equal partners in change.

In addition, our continuing perusal of NRM literature convinces us of a global shortage of needed skills - to conduct research, facilitate collaboration and learning loops, formalize plans and develop policies that respect the above observations. Awareness of this shortcoming has been one of our motivations for pulling together the analyses in this book (and a forthcoming collection on the same topic). We have introduced some tools and procedures we found useful in conducting ACM; shown how these have evolved; and considered how such approaches can be used beyond the forest.

In Chapters 2, 4 and 5, we looked at the details of ACM and PAR processes (processes which can most usefully be seen as an overlapping part of a Venn diagram). Within our own (the editors') work, we have seen PAR as a tool to help bring about ACM, though not everyone sees it that way. Both concepts, however, include iterative learning cycles, one of ACM's most central attributes. All three of these chapters, using different methods and styles, convey the process of ACM as well as some evaluation of its functioning (in Bolivia and Uganda).

We then discussed more specific issues that need addressing in any ACM project: ensuring good interdisciplinary collaboration (Chapter 3); training participants in the approach itself (Chapter 6); and one way groups can monitor their interactions to ensure inclusivity (Chapter 7).

In Chapters 1, 8 and 9, we delve into first the theoretical background of the original conceptualization of ACM, along with reflections on the editors' varied perspectives and backgrounds (1); then more recent theories and considerations as ACM has evolved, focusing particularly on issues of power (8); and finally, an overview of the use of action research in various sectors and contexts, demonstrating its versatility and broad applicability, a topic we have continued in this chapter (10), emphasizing attempts to move up and outwards with ACM-style approaches.

Meanwhile, we will make other efforts to encourage the development of the skills needed to conduct research and action that attend to issues like those listed in Box 10.1. Colfer and Larson are both also working, for instance, on forest landscape restoration, where the lack of attention to local level realities is striking (also identified, e.g., in collections by Mansourian and Parrotta 2018 or Butler and Schultz 2019). They and their colleagues are working to rectify this situation (e.g., in this volume and in one by Katila et al. under development). Larson and her team continue to work on multi-stakeholder platforms and processes, not simply to support their existence but also their quality, with regard to equity and social inclusion (see https://www.cifor.org/toolboxes/tools-for-managing-land scapes-inclusively/). Prabhu's work in agroforestry has identified shortcomings in their research as well, much of it captured in the agricultural cases in this chapter.

About the time this book appears, the global community will be preparing to meet to discuss the critical contributions that smallholder agriculture, forest-dependent people and those involved in the supply chains that originate 
in the forested and treed landscapes of our small planet, as well as discussions on preventing - or exacerbating - forest and biodiversity loss, greenhouse gas emissions and losses of soil fertility. If there is anything we can offer the global community it is this: these people are both exploiters and stewards of the land. How we view them, and how they view themselves, will determine which trajectory or spiral of change emerges - towards improvement or towards further degradation. The triskelion is agnostic about its direction - it can devour or protect. ACM offers a spiral of improvement and empowerment, where people are viewed and treated, and view themselves, as inter-generational stewards of all that the land produces, tangible and intangible.

\section{Notes}

1 A clear use of "ACM" as the desired endpoint as well as the process of getting there.

2 Three draft chapters for our second ACM volume document changes over time (since the early 2000s): two in Indonesia, where national conflict levels have been low and success substantial (e.g., successful formalization of local management rights in a local forest, widespread trust among stakeholders at different levels, and continuing collective action locally; Yuliani et al. 2021 (in draft form), Liswanti, Tamara, and Arwida 2021 (in draft)); one in Zimbabwe, where some local capabilities linger, but efforts to institutionalize triskelion style processes at higher levels stalled due to national crises, political and economic implosion and the disappearance of trained personnel in the Ministry of Forestry (Kozanayi et al. 2021 (in draft)).

3 For examples from earlier work, see e.g., Wiliam-deVries (2006) for an approach that successfully overcame Islamic concerns about ACM, feared to be trying to negate women's "legitimate fate" as submissive homemakers in Indonesia; or Bolaños and Schmink (2005) for community antagonism to women's involvement in logging enterprises in Bolivia.

4 See e.g., Colfer and Pfund (2011) for a CIFOR-based comparative study; or Butler and Schultz (2019) for a rather similar, US-based collaborative programme operating at a larger landscape level (also Colfer and Prabhu 2021 (in draft)).

5 Clearly, we can and often do use them for specific purposes within the umbrella of ACM.

6 That these authors from Jambi and Zimbabwe respectively, conducted these return visits without any financial incentives is evidence of their continuing interest in the approach and its impacts. Indeed, we provided no funding for the participation of any of the authors of this book (though some have been able to consider it part of their normal job).

7 Two initial sites had trouble nearly from the beginning (Ghana, Kyrgyzstan).

8 Unfortunately, this image does not fully capture the evolving and responsive aspect of the process.

9 The researchers worked with an inter-institutional working group in developing the second Turkana County Integrated Development Plan (CIDP), led by the Department of Finance and Economic Planning.

10 These two kinds of committees were extremely helpful in the original ACM programme as well.

11 CIFOR's Landscape Mosaics programme, in five countries, had similarly worded planning documents; but the learning and empowerment processes were never truly implemented in the field, so the anticipated community benefits were unlikely to have been forthcoming. Hopefully, Regreening Africa has learned from such shortcomings elsewhere. 
12 This was partly because of the dearth of information about life at local scales being taken into account in forest policymaking at the time (a similar rationale to that of Women in Development specialists in the 1970 s who were filling a gap before attending to gender dynamics).

\section{References}

Bolaños, Omaira, and Marianne Schmink. 2005. "Women's Place is Not in the Forest: Gender Issues in a Timber Management Project in Bolivia.” In The Equitable Forest: Diversity, Community and Resource Management, edited by Carol J. Pierce Colfer. Washington, DC: Resources for the Future/CIFOR.

Butler, William H., and Courtney A. Schultz, eds. 2019. A New Era for Collaborative Forest Management: Policy and Practice Insights from the Collaborative Forest Landscape Restoration Program. London: Earthscan/Routledge.

CIFOR. 1999. CEI Toolbox. 9 vols. Bogor, Indonesia: CIFOR.

Colfer, Carol J. Pierce, ed. 2005. The Equitable Forest: Diversity, Community and Resource Management. Washington, DC: RFF/CIFOR.

Colfer, Carol J. Pierce, and Jean-Laurent Pfund, eds. 2011. Collaborative Governance of Tropical Landscapes. London: Earthscan, CIFOR.

Colfer, Carol J. Pierce, and Ravi Prabhu. 2021 (in draft). "From Sustainable Forest Management to Forest Landscape Restoration: Comparison of Two Participatory Approaches." In ACM Volume 2, edited by C. Colfer, R. Prabhu and A. Larson.

Colfer, Carol J. Pierce, Jean-Laurent Pfund, with Etienne Andriamampandry, Stella Asaha, Amandine Boucard, Manuel Boissière, Laurène Feintrenie, Verina Ingram, Emmanuel Lyimo, Endri Martini, Salla Rantala, Michelle Roberts, Terry Sunderland, Zora Lea Urech, Heini Vihemaki, Vongvilai Vongkhamsao, and John Daniel Watts. 2011. "An Introduction to Five Tropical Landscapes, their People and their Governance." In Collaborative Governance of Tropical Landscapes, edited by Carol J. Pierce Colfer and Jean Laurent Pfund, 1-34. London: Earthscan.

Colfer, Carol J. Pierce, Ramadhani Achdiawan, Hasantoha Adnan, Moira Moeliono, Agus Mulyana, Elok Mulyoutami, James R. Roshetko, E. Linda Yuliani, with Balang, and LepMil. 2015a. "Preparing the Ground for Better Landscape Governance: Gendered Realities in Southern Sulawesi." Forests, Trees and Livelihoods 24 (1): 59-83. http://dx. doi.org/10.1080/14728028.2014.951002.

Colfer, Carol J. Pierce, Ramadhani Achdiawan, James M. Roshetko, Elok Mulyoutami, E. Linda Yuliani, Agus Mulyana, Moira Moeliono, Hasantoha Adnan, and Erni. 2015b. "The Balance of Power in Household Decision-Making: Encouraging News on Gender in Southern Sulawesi." World Development 76: 147-164.

Cronkleton, Peter, Deborah Barry, Juan M. Pulhin, and Sushil Saigal. 2010. "The Devolution of Management Rights and the Co-Management of Community Forests." In Forests for People: Community Rights and Forest Tenure Reform, edited by Anne Larson, Deborah Barry, Ganga Ram Dahal and Carol J. Pierce Colfer, 43-68. London: Earthscan/CIFOR.

Evans, Kristen, Sandra J. Velarde, Rocio P. Prieto, Sheila N. Rao, Sandra Sertzen, Karina Dávila, Peter Cronkleton, and Wil De Jong, eds. 2006. Field Guide to the Future: Four Ways for Communities to Think Ahead. Nairobi, Kenya: CIFOR, ASB, ICRAF.

Evans, Kristen, Selmira Flores, Anne M. Larson, Roberto Marchena, Pilar Müller, and Alejandro Pikitle. 2017. "Challenges for Women's Participation in Communal Forests: 
Experience from Nicaragua's Indigenous Territories." Women's Studies International Forum 65: 37-46.

Evans, Kristen, Anne M. Larson, and S. Flores. 2020. "Learning to Learn in Tropical Forests: Training Field Teams in Adaptive Collaborative Management, Monitoring and Gender." International Forestry Research 22 (2): 189-198.

Fisher, Micah R., Timothy Workman, Agus Mulyana, Balang Institute, Moira Moeliono, E. Linda Yuliani, Carol J. Pierce Colfer, and Urban El Fatih Bani Adam. 2020. "Striving for PAR Excellence in Land Use Planning: Multi-stakeholder Collaboration on Customary Forest Recognition in Bulukumba, South Sulawesi." Land Use Policy 99: 102997.

Flores, Selmira, Kristen Evans, Anne M. Larson, Alejandro Pikitle, and Roberto Marchena. 2016. "Participation of Rural Indigenous Women in Community Governance." CIFOR InfoBrief 151: 4.

Gnych, Sophia, Steven Lawry, Rebecca McLain, Iliana Monterroso, and Anukram Adhikary. 2020. "Is Community Tenure Facilitating Investment in the Commons for Inclusive and Sustainable Development?" Forest Policy and Economics 111.

Guijt, Irene. 2007. Negotiated Learning: Collaborative Monitoring for Forest Resource Management. Washington, DC: RFF/CIFOR.

Hughes K., Oduol J., Kegode H., Ouattara I., Vagen T., Winowiecki L. A., Bourne M., Neely C., Ademonla D. A., Carsan S., Van Schoubroeck F., and Chomba S. 2020. Regreening Africa Consolidated Baseline Survey Report. Nairobi, Kenya: World Agroforestry. Indriatmoko, Yayan, Linda Yuliani, Yunety Tarigan, Farid Gaban, Firkan Maulana, Dani Wahyu Munggoro, Dicky Lopulalan, and Hasantoha Adnan, eds. 2007. Dari Desa ke Desa: Dinamika Gender dan Pengeloalaan Kekayaan Alam [From Village to Village: Gender Dynamics and the Management of Nature's Wealth]. Bogor, Indonesia: CIFOR.

Katila, Pia, Carol J. Pierce Colfer, Wil Dejong, Glenn Galloway, Pablo Pacheco, and Georg Winkel, eds. n.d. under development. Restoring Forests and Trees for Sustainable Development: Policies, Practices, Impacts and Ways Forward.

Komarudin, Heru, Yuliana L. Siagian, Carol J. Pierce Colfer, with Neldysavrino, Yentirizal, Syamsuddin, and Deddy Irawan. 2012. "The Role of Collective Action in Securing Property Rights for the Poor: A Case Study in Jambi Province, Indonesia." In Collective Action and Property Rights for Poverty Reduction, edited by Esther Mwangi, Helen Markelova and Ruth Meinzen-Dick, 235-269. Philadelphia, PA: University of Pennsylvania Press.

Kozanayi, W., R. Nyirenda, T. Mutimukuru, F. Matose, M. Ngwenya, and L. Sibanda. n.d. under development. Sustaining ACM Processes: Challenges and Opportunities from Mafungautsi State Forest, Gokwe, Zimbabwe.

Liswanti, Nining, Ade Tamara, and Shintia Arwida. 2021 (in draft). n.d. under development. Trust Building in a Multi-stakeholder Forum in Jambi, Indonesia.

Mansourian, Stephanie, and John Parrotta, eds. 2018. Forest Landscape Restoration: Integrated Approaches to Support Effective Implementation. New York: Routledge/Earthscan.

Marald, Erland, Camilla Sandstrom, Annika Nordin, and others. 2017. Forest Governance and Management Across Time: Developing a New Forest Social Contract. London: Routledge/ Earthscan.

McDougall, Cynthia, Bishnu Hari Pandit, Mani Ram Banjade, Krishna Prasad Paudel, Hemant Ojha, Manik Maharjan, Sushila Rana, Tara Bhattarai, and Sushma Dangol. 2009. Facilitating Forests of Learning: Enabling an Adaptive Collaborative Approach in Community Forest User Groups: A Guidebook. Bogor, Indonesia: CIFOR.

McDougall, C., H. Ojha, M. Banjade, B.H. Pandit, T. Bhattarai, M. Maharjan, and S. Rana. 2010. Forests of Learning: Experiences from Research on an Adaptive Collaborative Approach to Community Forestry in Nepal. Bogor, Indonesia: CIFOR. 
McDougall, Cynthia L., Cees Leeuwis, Tara Bhattarai, Manik R. Maharjan, and Janice Jiggins. 2013. "Engaging Women and the Poor: Adaptive Collaborative Governance of Community Forests in Nepal." Agriculture and Human Values 30: 569-585.

Neely, C. and M. Bourne. 2021. "Regreening Africa Joint Reflective Learning Missions 2020." Nairobi: ICRAF. https://regreeningafrica.org/wp-content/uploads/2021/04 /2020_Regreening-Africa-JRLM-Summary_ONLINE_31_03_21.pdf

Neely, C.L., M. Bourne, S. Chesterman, T-G. Vågen, V. Lekaram, L.A. Winowiecki, and R. Prabhu. 2021. Inclusive, Cross-sectoral and Evidence-based Decision Making for Resilience Planning and Decision Making in a Devolved Context. European Journal of Development Research 33 (40): 1115-1140.

Barletti Sarmiento, Juan Pablo, and Anne M. Larson. 2020. "Paradigms for Participation in Multi-stakeholder Forums: Lessons from a Realist Synthesis Review." CIFOR Infobrief 281.

Vågen, T.-G., L. A. Winowiecki, C. Neely, S. Chesterman, and M. Bourne. 2018. "Spatial Assessments of Soil Organic Carbon for Stakeholder Decision-making: A Case Study from Kenya." Soil 4: 259-266.

Vanclay, Jerome K., Ravi Prabhu, and Fergus Sinclair. 2003. "Special Issue on Participatory Modelling of Community Forest Landscapes." Small-Scale Forest Economics, Management and Policy 2 (2): 117-326.

Vanclay, Jerry, Ravi Prabhu, and Fergus Sinclair. 2006. Realizing Community Futures: A Practical Guide to Harnessing Natural Resources. London: Earthscan.

Wiliam-deVries, Dede. 2006. Gender Bukan Tabu: Catatan Perjalanan Fasilitasi Kelompok Perempuan di Jambi [Gender is not Taboo: Field Notes on Facilitating Women's Groups in Jambi. Bogor, Indonesia: CIFOR.

Winowiecki, Leigh Ann, Mieke Bourne, Christine Magaju, Constance Neely, Boniface Massawe, Patricia Masikati, Tor-Gunnar Vågen, Faith Musili, Muhammad Nabi, Anthony Nguyo, Hadia Seid, Kiros Hadgu, Aikande Shoo, Howard Tembo, Floyd Chipatela, Sabrina Chesterman, Karl Hughes, Emmanuel Temu, Anthony Anderson Kimaro, and Fergus Sinclair. 2021. "Bringing Evidence to Bear for Negotiating Tradeoffs in Sustainable Agricultural Intensification Using a Structured Stakeholder Engagement Process." International Journal of Agricultural Sustainability: 1-23. doi:10.1080/14735903. 2021.1897297.

Wollenberg, Eva, David Edmunds, and Louise Buck. 2000. Anticipating Change: Scenarios as a Tool for Adaptive Forest Management (a Guide). Bogor, Indonesia: CIFOR.

Wollenberg, Eva, David Edmunds, Louise Buck, Jefferson Fox, and S. Broch, eds. 2001a. Social Learning in Community Forests. Bogor, Indonesia: CIFOR.

Wollenberg, Eva, Jon Anderson, and David Edmunds. 2001b. "Pluralism and the Less Powerful: Accommodating Multiple Interests in Local Forest Management." International Journal of Agricultural Resources, Governance and Ecology 1 (3/4): 199-222.

Yuliani, Elizabeth Linda, Hasantoha Adnan, Carol J. Pierce Colfer, and Yayan Indriatmoko. 2015. "Problem-solving Versus Appreciative Inquiry Approaches in Community-based Conservation." Forests, Trees and Livelihoods: 97-111. doi: 10.1080/14728028.2014.954638.

Yuliani, Linda, Moira Moeliono, Yanti Kusumanto, Marzoni, Effi Permatasari, Hasantoha Adnan, Yayan Indriatmoko, and Carol J. Pierce Colfer. 2021. n.d. in preparation. "Revisiting Baru Pelepat: Life after ACM." 
$\Longrightarrow$ Taylor \& Francis Taylor \& Francis Group

http://taylorandfrancis.com 